\title{
Effect of Power and Time in Pectin Production from Cocoa Pod Husk Using Microwave-Assisted Extraction Technique
}

\author{
Maya Saraha, ${ }^{a}$, M. Faizul Hishamª, Mushila Rizkia ${ }^{a}$, and Ricka Erwinda ${ }^{a}$ \\ ${ }^{a}$ Chemical Engineering Department, Universitas Sumatera Utara, Indonesia \\ ${ }^{b}$ Centre of Sustainable Energy and Materials, Universitas Sumatera Utara, Indonesia
}

\begin{abstract}
Investigation on microwave technique to extract pectin from cocoa pod husk in this study carries out using citric acid and hydrochloric acid ( $\mathrm{HCl})$. Extraction proceeds at various microwave powers (180, 300, 450, 600 Watt) and irradiation periods (10, 15, 20, 25, 30 minutes). This study observed effect of power and time to yield and quality of pectin. Yield of pectin increased at elevated power and time either with citric acid or $\mathrm{HCl}$ solvent. Overall pectin quality in this study meet the IPPA quality factor exclude water content which relatively higher. MAE treatment with citric acid using microwave power of 300 Watt for 30 minutes resulted yield of $42 \%$ and high pectin quality as compare to MAE treatment with $\mathrm{HCl}$. The best pectin product in this study has moisture content of $8 \%$, ash content of $10 \%$, equivalent weight of $714.29 \mathrm{mg}$, methoxyl content of $4.8 \%$ and galacturonate level of $43 \%$. C2020. CBIORE-IJRED. All rights reserved
\end{abstract}

Keywords: Cocoa, extraction, microwave, pectin, power

Article History: Received: Oct 19, 2019; Revised: December 26, 2019; Accepted: January 20, 2020; Available online: February 15, 2020

How to Cite This Article: Sarah, M., Hisham, M.F., Rizki, M., and Erwinda, R. (2020) Effect of Power and Time in Pectin Production from Cocoa Pod Husk Using Microwave-Assisted Extraction Technique. International Journal of Renewable Energy Development, 9(1), 123-130 https://doi.org/10.14710/ijred.9.1.123-130

\section{Introduction}

Pectin is originally presence in vegetables and fruits (Maran et al. 2015). It is a fibre component in the lamella layer and primary cell wall of plant (Swamy and Muthukumarappan, 2017) that consists of d-galacturonic acid backbone linked by a-(1.4) glycosidic bond. Some carboxyl groups of pectin polymer esterified into methoxyl groups (Lefsih et al. 2017). Food industry usually used pectin as agents of gelling, stabilizing and thickening (Swamy and Muthukumarappan, 2017). In tropical countries, pectin was found in banana (Swamy and Muthukumarappan, 2017 and Qiu et al. 2010), passion fruit (Oliveira et al. 2016), cocoa (Theobroma cacao) (Chan and Choo, 2013), Opuntia ficus indica (Lefsih et al. 2017), pumkin (Shkodina et al. 1998) etc. Daily activity and manufacture of fruit juice that disposes biomass are source of commercial natural pectin such as fruit peels and pod husk. Some studies reported pectin isolation from banana peels (Swamy and Muthukumarappan, 2017), peels of passion fruit (Oliveira et al. 2016) and cocoa husk (Chan and Choo, 2013).

Basically, pectin is extracted from plant at high temperature using sulfuric, phosphoric, nitric, hydrochloric and citric acid as solvent (Shkodina et al. 1998). Methods to isolate pectin from plant were reported by several authors such as soxhlet extraction, maceration and stirring extraction. Rather than common isolation methods, Wang et al. (2007) and Shkodina et al. (1998) reported microwave-assisted extraction (MAE) (Oliveira et al. 2016) and enzymatic method (Chan and Choo, 2013) to extract pectin from plants respectively. MAE is introduced to improve extraction method using microwave energy. MAE technology is a technique to extract dielectric materials in plant by microwave energy. The MAE performs fast extraction process with minimum energy requirement and consumes less solvent. This process obtains higher yield of pectin and proceeding with higher accuracy and precision (Sirotek et al. 2004). MAE at laboratory scale was reported successful while extracting pectin from Opuntia ficus indica (Lefsih et al. 2017) and banana peels (Oliveira et al. 2016). Instead of extraction at high temperature, utilization of microwave may assist chemical processing and has reported by several authors. Sukaribin and Khalid (2009), Cheng et al. (2011), Sarah and Taib (2017) and Sarah et al. (2018a) reported utilization of microwave energy for heating and sterilization process. Implementation of microwave energy in chemical processing is due to instant heat generation inside the material from water molecule reorientation that increases interior temperature during heating process (Sarah, 2018).

\footnotetext{
* Corresponding author: mayasharid@yahoo.com
} 
In this study, microwave energy is used to assist pectin extraction from cocoa pod husk. Phenomena instant and rapid heating from microwave energy utilization in this study aims to facilitate temperature required for extraction process. Qiu et al. (2010) reported parameters associated with yield and pectin quality during extraction process such as $\mathrm{pH}$, temperature, extraction time, agitation and solid to liquid ratio (Swamy and Muthukumarappan, 2017). In the case extraction process by microwave irradiation, level of microwave power during extraction process also taken into consideration instead of previous parameters. In this study investigation is carried out to evaluate microwave-assisted extraction of pectin from cocoa pod husk using citric acid and $\mathrm{HCl}$ as solvent. In this study, we compare product quality as the results of process performance by utilizing citric acid as has been reported by authors elsewhere ((Sarah et al. 2018b) earlier and $\mathrm{HCl}$. $\mathrm{HCl}$ economically cheaper than citric acid but it is also known as a toxic solvent, therefore while pectin obtained from extraction with citric acid may use as food ingredient and additive, pectin resulted from extraction with $\mathrm{HCl}$ is non-food grade. This study evaluates potency of both citric acid and $\mathrm{HCl}$ utilization in pectin production from cocoa peel at laboratory scale and their possible implementation on the commercial pectin production.

\section{Materials and Methods}

\subsection{Materials}

This study uses Theobroma cacao pod husk taken from local plantation located at Pangkalan Brandan, Sumatera Utara Province, Indonesia and chemicals such as citric acid, $\mathrm{HCl}$, ethanol, silver nitrate solution, sodium chloride, sodium hydroxide, and phenolphthalein supplied by PT Merck Tbk and distil water obtained from local chemical supplier (PT Rudang Medan). Extraction carried out in an Erlenmeyer placed inside domestic microwave oven (Samsung model ME731K) irradiated by microwave energy with frequency of $2450 \mathrm{MHz}$ and power output of 800 Watt. This experiment carried out at Organic Chemistry Laboratory of Chemical Engineering Department of Universitas Sumatera Utara.

\subsection{Pre-treatment}

The cocoa pod husk is cleaned upon arrival from plantation and put inside basin with lime ash solution to remove the gums. The pod is cut into slices with dimension of approximately $2 \times 2 \times 0.5 \mathrm{~cm}$ each and dried prior size reduction. Drying carried out for about 12 hours, consist of sun drying for approximately 8 hours, and drying using conventional oven at temperature of $40^{\circ} \mathrm{C}$ for approximately 4 hours. The dried cocoa slices are then reduced their size into 60 mesh using a blender (Miyako model BL-151PFAP No 34060052217).

\subsection{MAE processes and pectin characterization}

Cocoa pod powder with moisture content of approximately $10 \%$ are diluted with citric acid $(\mathrm{pH}=1.5)$ or $0.2 \mathrm{~N} \mathrm{HCl}$ solution ( $\mathrm{pH}$ of 1.6) and irradiated by microwave energy at various microwave power (180, 300, 450 and $600 \mathrm{~W}$ ) for 10 to 30 minutes with 5 minutes intervals respectively. Separation carried out using filter paper (Whatman no 2) and filtrate is heated and stirred at temperature approximately $95^{\circ} \mathrm{C}$ until volume is reduced by $50 \%$. Prior cools the viscous filtrate, ethanol is added to precipitate the pectin. Ethanol is also required to remove residual citric acid or $\mathrm{HCl}$. The pectin is then dried at temperature of $40^{\circ} \mathrm{C}$ for approximately 8 hours. The dried pectin is then ready for characterization to determine moisture and ash content (British Standard Institute, 1998), so as their equivalent weight, content of methoxyl and galacturonic acid (Ranggana, 2000). The best MAE results in this study is identified further their functional group utilizing FTIR IR Prestige 21 model A21004602022 LP series (Shimadzu) with wavenumber ranging between 400 to $400\left(\mathrm{~cm}^{-1}\right)$. FTIR spectra with their peak absorption indicated some functional group in pectin sample such as hydroxyl group $(\mathrm{O}-\mathrm{H})$, carboxyl group $(\mathrm{C}=\mathrm{O})$ and $\mathrm{C}-\mathrm{O}$. The peak between 3500 and $3300 \mathrm{~cm}^{-1}$ is due to stretching of hydroxyl group, while peaks lies between 1850 and $1500 \mathrm{~cm}^{-1}$ are associated with the vibrational modes of a carboxyl group that indicates double bond from the carboxylic acid methyl ester. Others band lies between 1320 and $1210 \mathrm{~cm}^{-1}$ is associated with C-O (Coates, 2006). This characterization carried out at Organic Chemistry Laboratory of Chemical Engineering Department of Universitas Sumatera Utara, while FTIR test conducted at Pharmacy Faculty of Universitas Sumatera Utara.

\section{Results and Discussion}

The MAE process in this study has successfully extracted the pectin from cocoa pod husk using citric acid and $\mathrm{HCl}$. This study evaluates effect of extraction time and microwave power on yield, content of moisture and ash, methoxyl and galacturonate levels. MAE process performance may be evaluated using quality indicators with respect to International Pectin Producers Association (IPPA) Quality Standard (IPPA, 2014) at various irradiation period and microwave power.

\subsection{Yield of pectin obtained from MAE treatment at various time and power}

Overall, extraction of pectin from cocoa pod husk with citric acid under microwave irradiation yielded pectin higher as compare to treatment with $\mathrm{HCl}$ solvent. While treatment with citric acid obtained yield of pectin as high as $47 \%$, the other treatment only yielded pectin of $2.2 \%$. Treatment with citric acid yielded pectin approximately range between $12-30 \%$; $18-32 \%$; $29-32 \%$; $30-40 \%$, and 28 $47 \%$ respectively, while treatment with $\mathrm{HCl}$ yielded pectin approximately ranged between $0.4-1.4 \%$; $0.45-1.5 \%$; 1.1 $1.8 \%$; and $1.3-2.2 \%$ respectively from extraction for 10 to 30 minutes at various power of $180,300,450$ and 600 Watt.

Figure 1 shows effect of extraction time and microwave power to yield of pectin obtained from extraction with citric acid and $\mathrm{HCl}$. Prolong heating at constant microwave power to extend extraction time from 10 to 30 minutes using citric acid as solvent as showed in Figure 1(a) yielded high pectin, while maximum time to extract pectin from cocoa pod husk with $\mathrm{HCl}$ is 20 minutes. On the contrary, prolong heating from 20 to 30 minutes decrease pectin yield obtained from extraction with $\mathrm{HCl}$ as shown in Figure 1(b). Time increment of MAE treatment with citric acid (Figure 2(a)) resulted significant increment of 
pectin product. This is especially observed from MAE treatment at low power level (180 Watt). For MAE treatment at 600 Watt of power, no significant yield increment observed after 25 minutes. Similar power effect phenomena observed for MAE treatment with $\mathrm{HCl}$, only in this case level of yield increment is very low and will be insignificant if compare to MAE treatment with citric acid.

The best process condition to obtain the highest pectin product for MAE process with citric acid at laboratory scale is extraction for 30 minutes using power of $300 \mathrm{Watt}$ (yielded pectin of $47 \%$ ) while MAE process with $\mathrm{HCl}$ is 15 minutes using power of 600 Watt (yield of $2.2 \%$ ) or 20 minutes using power of 450 Watt (yielded pectin of $1.8 \%$ ). The MAE treatment with $\mathrm{HCl}$ offered fast process but energy intensive while the second one is slower but save more energy.

In this study, extraction time associated with time required for preliminary heating to attain extraction temperature plus extraction period until maximum pectin obtained. The presence of citric acid or $\mathrm{HCl}$ and microwave energy accelerate process to achieve temperature required to release pectin trapped in the cell tissue of the cocoa powder in solvent solution in acidic environment. High temperature of MAE process increased the kinetic energy of the cocoa solution and facilitates the diffusion of citric acid and $\mathrm{HCl}$ into the tissue cells.
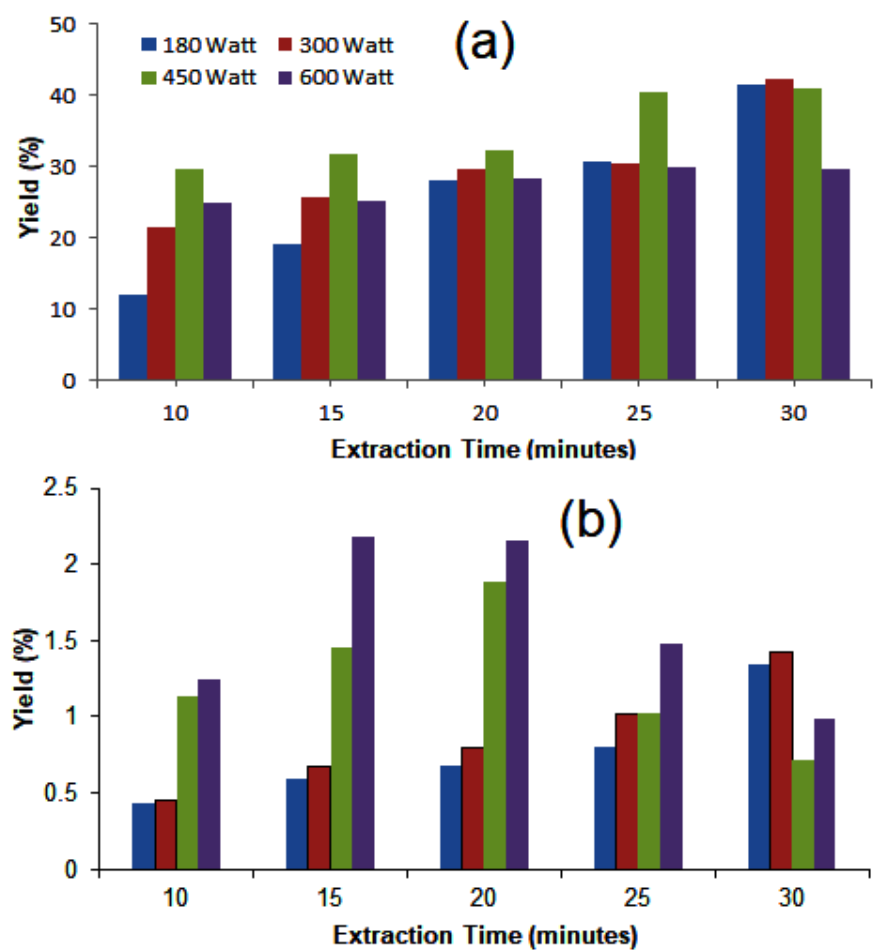

Fig. 1 Pectin yielded after extraction under microwave irradiation at various power and time using citric acid (a) and $\mathrm{HCl}$ (b) as solvent

\subsection{Quality of pectin product obtained from MAE treatment at various time and power}

This study evaluates the quality of pectin obtained from both MAE proses with citric acid and $\mathrm{HCl}$ with respect to standard proposed by International Pectin Producers Association (IPPA) (IPPA, 2014). Qualities of pectin evaluated in this study are content of moisture, ash, galacturonic acid, equivalent weight, and methoxy. Figure
2, 3, 4 and 5 show effect of extraction time and microwave power on quality of pectin in this study.

\section{2.a Moisture content}

Moisture content usually represented by water content affects shelf life of pectin. Water enhances oxidation and hydrolysis of pectin by microbial activity. Figure 2 shows water content influenced significantly by microwave power for MAE treatment with $\mathrm{HCl}$ solvent, but slightly insignificant for treatment with citric acid. Pectin obtained from MAE with citric acid and $\mathrm{HCl}$ treatment using 180 Watt of power for 10 minutes contain water approximately $11.5 \%$ and $9.8 \%$ respectively. It is observed that power increment from 180 to 450 Watt and/or 600 Watt in MAE treatment with $\mathrm{HCl}$ for 10 minutes reduced water content approximately $2 \%$, while treatment with citric acid only reduces water less than $1 \%$ if power increase from 180 to 450 Watt.
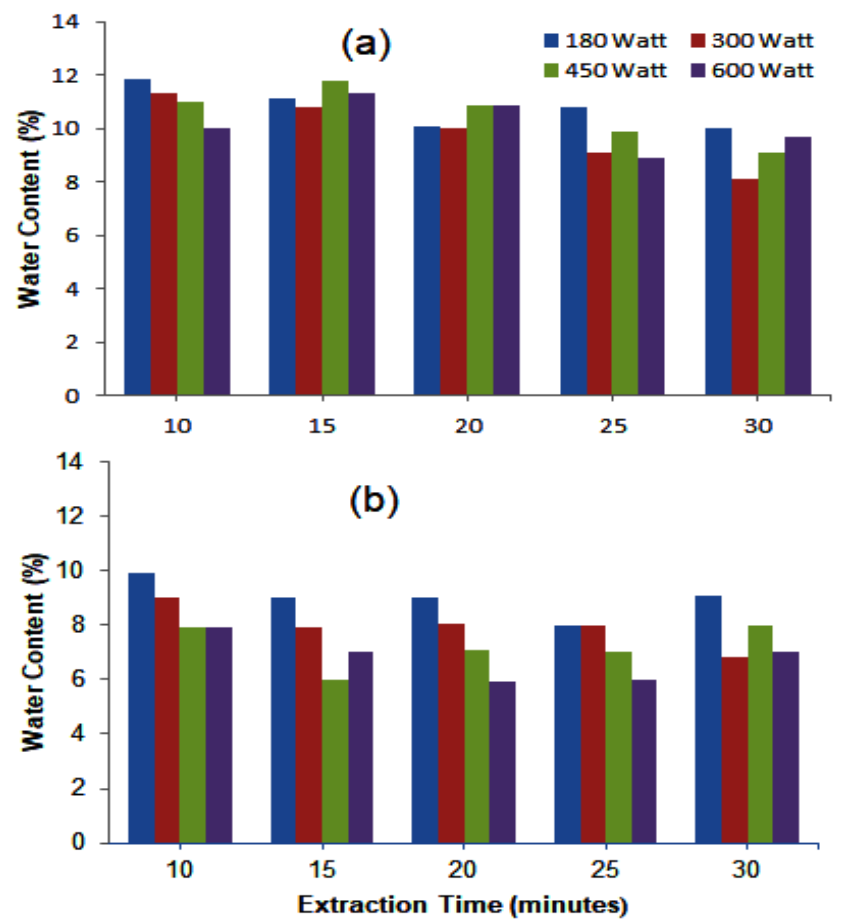

Fig. 2 Water content in pectin product after extraction at various microwave power and time using citric acid (a) and $\mathrm{HCl}$ (b) as solvent

Table 1 Quality factor of pectin product from MAE treatment with citric acid and $\mathrm{HCl}$.

\begin{tabular}{lcrr} 
Quality Factor & \multicolumn{1}{c}{$\begin{array}{c}\text { Citric } \\
\text { Acid }\end{array}$} & \multicolumn{1}{c}{ HCl } & \multicolumn{1}{l}{ IPPA } \\
\hline Methoxyl content (\%) & $2.5-6.5$ & $2.5-7.1$ & $2.5-7.2$ \\
Galacturonic acid (\%) & $25.0-58.0$ & $20.0-45.0$ & Min 35 \\
Moisture content (\%) & $7.8-11.8$ & $5.8-9.8$ & Max 12 \\
Ash content (\%) & $1.0-5.7$ & $5.0-10.0$ & Max 10 \\
Equivalent weight (mg) & $750-2990$ & $750-1650$ & $600-800$ \\
\hline
\end{tabular}

On the contrary, prolonged extraction time for MAE treatment with $\mathrm{HCl}$ in this particularly treatment less influences the water content of pectin product. No significant water reduced if time extended. Different situation observed for MAE treatment with citric acid. The water contained in pectin observed remain constant 
if extraction period extended from 10 to 20 minutes. After that water content of pectin obtain from treatment with high level of power decrease. Overall water of pectin in this study observed below maximum allowance moisture content in pectin according to IPPA standard (12\%) (IPPA, 2014). Overall water content resulted from this study is tabulated in Table 1.

\section{2.b Ash content}

Ash content in pectin indicates the purity level of pectin that mainly consists of $\mathrm{K}, \mathrm{Na}, \mathrm{Mg}$ and $\mathrm{Fe}$. It is influenced by 3 factors such as (1) the presence of inorganic material residues contained in cocoa pod husk, (2) method of extraction and (3) pectin insulation (Chen et al. 2014). High quality pectin is the pectin with high purity indicated by low ash content. This study observes ash contented in pectin obtained from MAE treatment with citric acid is lower than the one obtained from treatment with $\mathrm{HCl}$ solvent as shown in Figure 3.
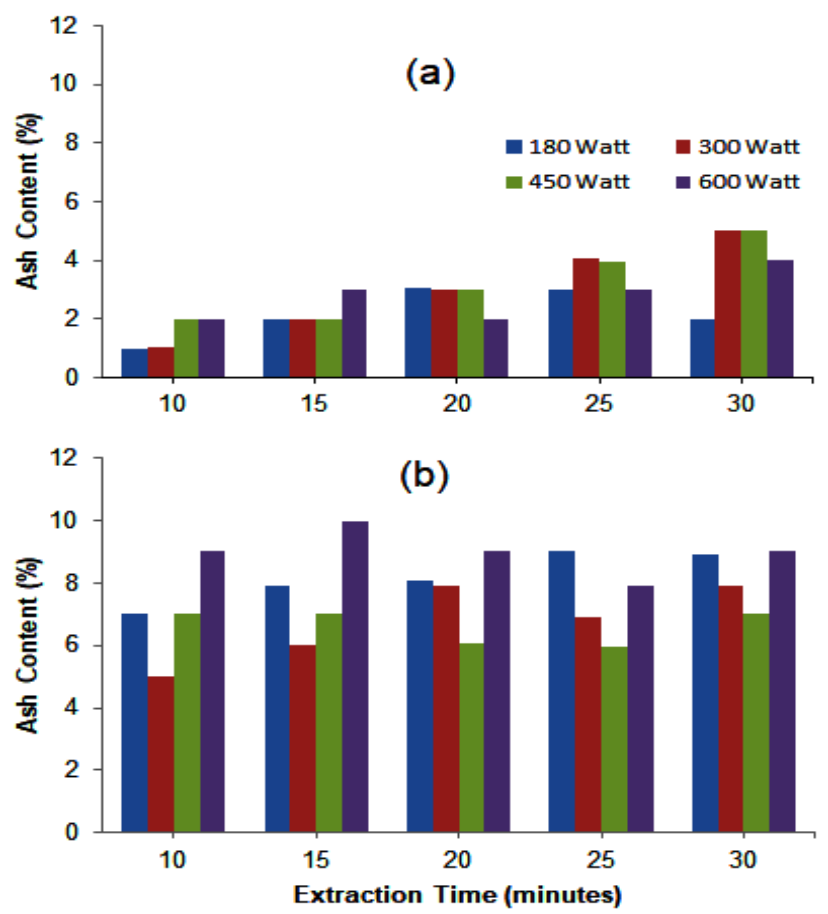

Fig. 3 Ash content in pectin product after extraction at various microwave power and time using citric acid (a) and $\mathrm{HCl}$ (b) as solvent

The result indicates MAE treatment with citric acid resulted high quality pectin due to their low ash content (1-5.7\%). Figure 3 shows ash contented in pectin obtained from extraction with citric acid influenced by both microwave power and extraction time. It increases or decrease their purity at the increment of microwave power and/or prolonged heating. Power increment at constant extraction time increase the ash content. This is because high microwave power and prolonged extraction time promote hydrolysis of proto pectin that results $\mathrm{Ca}$ and $\mathrm{Mg}$ content of pectin (Chen et al. 2014). For the example treatment at higher power (450 and 600 Watt) for 10 minutes results low grade pectin due their ash content higher as compared to treatment at lower microwave power (180 and 300 Watt).
MAE treatment with $\mathrm{HCl}$ solvent resulted high ash content as compare to treatment with citric acid. The ash content ranged between 5 to $10 \%$ and it remains constant even if extraction period extends from 10 to 30 minutes. Overall ash content in this study obtained from $5-10 \%$ or below IPPA standard. Maximum allowance ash content in pectin according to IPPA standard is maximum approximately 10\% (IPPA, 2014). Overall ash content resulted in this study is tabulated in Table 1.

\section{2.c Methoxyl content}

Among significant criteria for pectin quality is number of free esterified carboxyl group in the pectin that represented by methoxyl content. The methoxyl content indicates pectin quality with respect to sugar requirement for gel formation. Pectin with high level of methoxyl content can form gels in the presence of sugars and acids in certain composition, whereas low methoxyl pectin can form gel in the absence of sugars (Manrique and. Lajolo, 2002). Figure 4 shows extraction time and microwave power affect the methoxyl content of pectin.
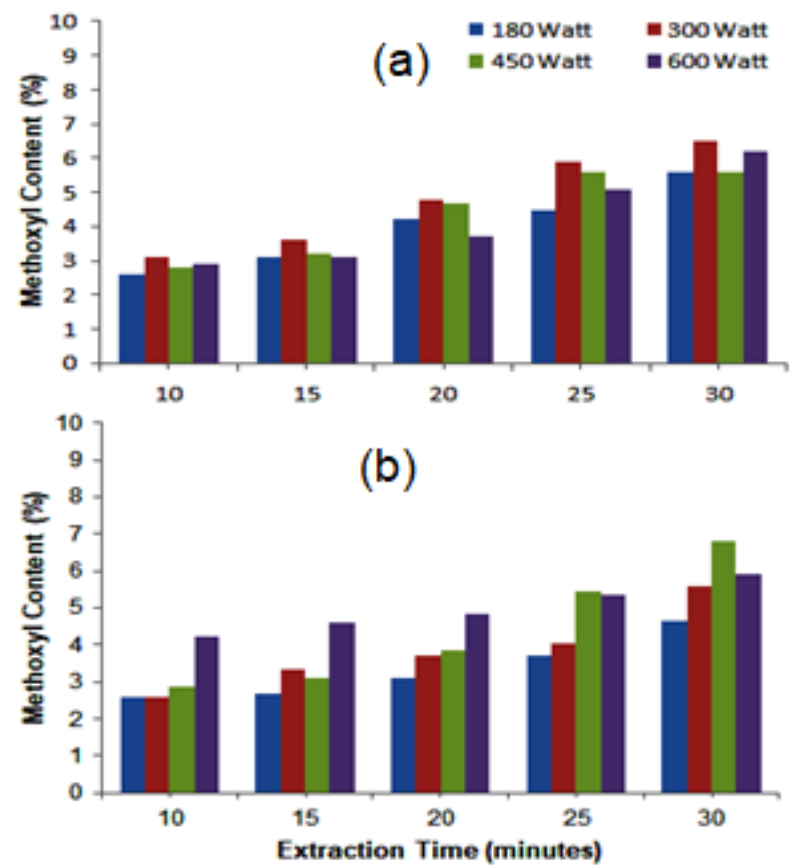

Fig. 4 Metoxyl contented in pectin product after extraction at various microwave power and time using citric acid (a) and $\mathrm{HCl}$ (b) as solvent

While power less significant on treatment with citric acid as shown in Figure 4(a), extraction time influences the methoxyl content in pectin. Methoxyl content is observed increase at increment of extraction time at constant microwave power due to hydrolysis of methyl ester group of pectin with the presence of citric acid. Different phenomena observed on MAE treatment with $\mathrm{HCl}$ acid as shown in Figure 4(b). Microwave power increment from 180 to 450 Watt is less significant on methoxyl content, but on the contrary significantly increase the methoxyl content if power level increase from 450 to 600 Watt. This situation observed during the first 20 minutes. Time also have less effect on the methoxyl content. Prolonged extraction from 10 to 20 and 25 minutes are not increase the methoxyl content significantly except for treatment 
using power of 450 Watt. Methoxyl content only increase significantly if extraction time extended from 25 to 30 minutes. Overall it can be concluded power and time less effect the methoxyl content on pectin yielded from MAE technique with citric acid.

With respect to methoxyl content in this study, the pectin obtained had the potency to be utilized in industry. Overall, methoxyl content resulted from MAE treatment with citric acid and $\mathrm{HCl}$ in this study ranged between 2.5 to $6.5 \%$ and 2.5 to $7.12 \%$ respectively. This methoxyl content meet the IPPA standard for low methoxyl content (2.5 to 7.2\%) (IPPA, 2014). Methoxyl content that indicated pectin quality resulted from this study is tabulated in Table 1.
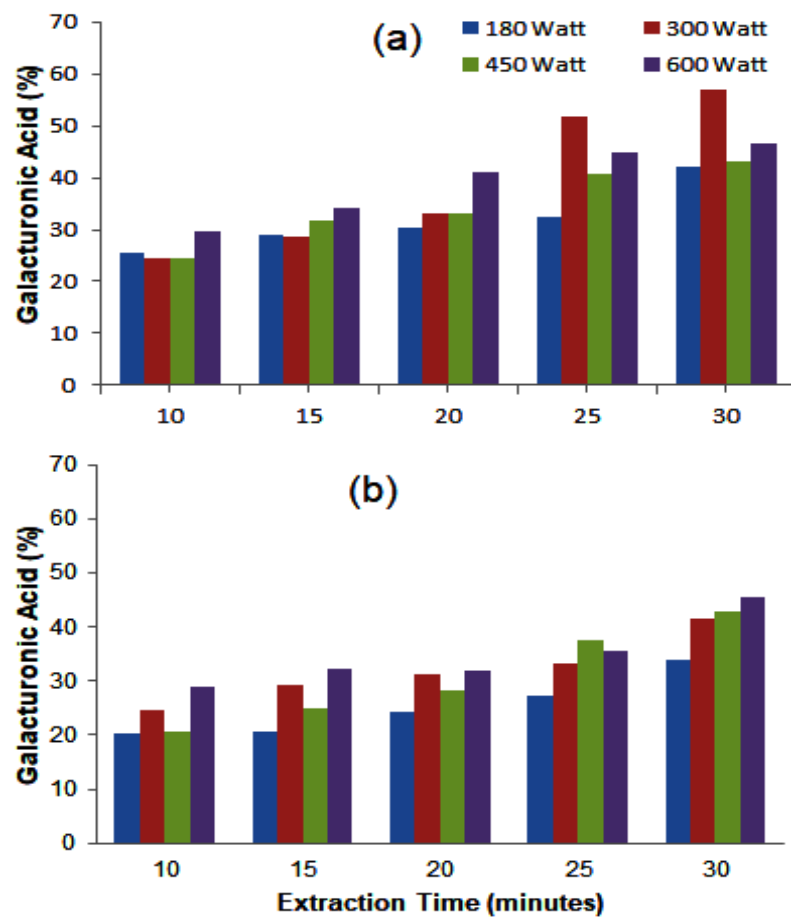

Fig. 5 Galacturonic acid level in pectin product after extraction at various microwave power and time using citric acid (a) and $\mathrm{HCl}$ (b) as solvent

\section{2.d Galacturonic acid}

The amount of pectin contained in flour particles is represented by their galacturonic acid level. It is an important feature used to evaluate structure and texture of pectin. Pectin with high galacturonic acid level has strong bonds during gel formation (Kalapathy and Proctor, 2001). Figure 5 shows galacturonic acid level in pectin sample obtained from MAE treatment with both citric acid and $\mathrm{HCl}$ acid increase along with the increment of extraction time at constant microwave power.

In this study, galacturonic acid contented in pectin yielded from treatment with citric acid and $\mathrm{HCl}$ acid are observed ranged between 25 to $58 \%$ and 20 to $45.37 \%$ respectively. Refer to IPPA standard, the minimum amount of galacturonate content allowed in pectin is approximately 35\% (IPPA, 2014). This indicates some MAE treatment produces pectin with galacturone acids content meet the IPPA standard especially MAE that carried out for 30 minutes using power of 300, 450 and 600 Watt respectively. Overall galacturonic acid resulted from this study is tabulated in Table 1.

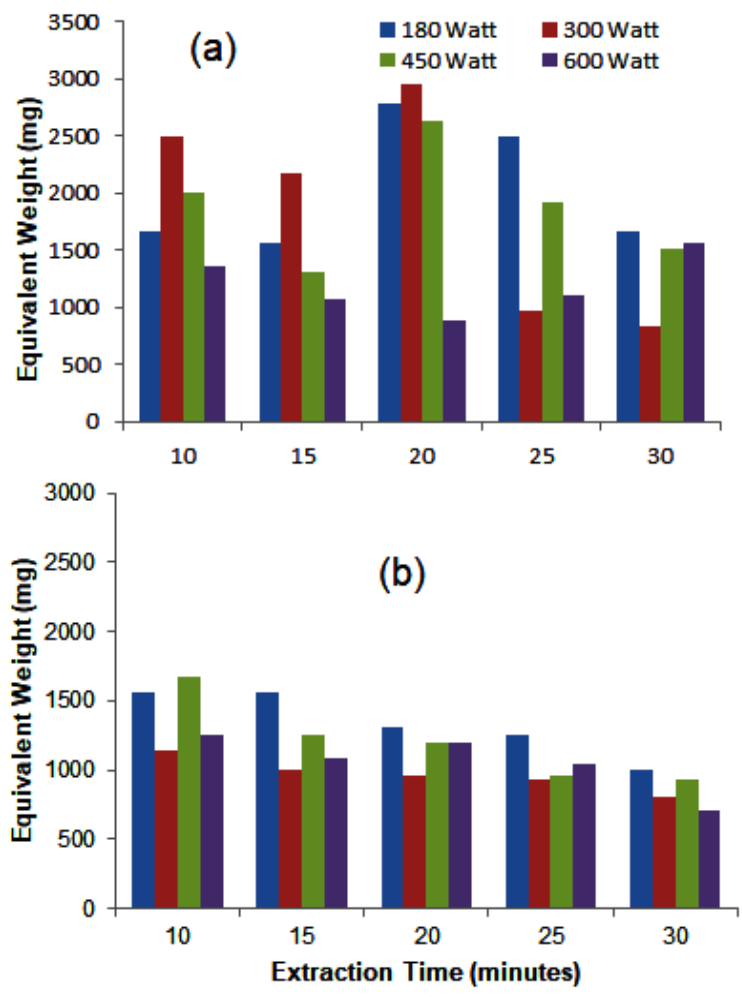

Fig. 6 Product equivalent weight after extraction at various microwave power and time using citric acid (a) and $\mathrm{HCl}$ (b) as solvent

\section{2.e Equivalent weight}

Figure 6 shows equivalent weight of pectin is influenced by extraction time. An equivalent weight is an indicator the presence of an anhydro uronic acid and degree of esterification. Overall equivalent pectin weights with citric acid and $\mathrm{HCl}$ treatments in this study are ranged from 750 to $2990 \mathrm{mg}$ and 750 to $1650 \mathrm{mg}$ respectively. The equivalent weight observed in this study is above the IPPA standard (600-800 mg) (IPPA, 2014) due to variability on raw material's quality and characteristics and extraction methods.

With respect to Figure 6, to obtain pectin with equivalent weight meet the IPPA standard, extraction should be carried out more than 30 minutes utilizing microwave power of 600 Watt. MAE treatment with citric acid at various microwave power results pectin with high equivalent weight if extraction carried out for 10 to 20 minutes as shown in Figure 6. Time extension from 20 to 30 minutes reduces the equivalent weight, but none of them meet IPPA standard. This study proposes high moisture content in this study contributes to total equivalent weight.

Different results observed from MAE treatment with HCL. Figure shows MAE treatment with $\mathrm{HCl}$ results lower equivalent weight as compare to treatment with citric acid, but above IPPA standard exclude for MAE treatment with $\mathrm{HCl}$ utilizing power of 600 Watt for about 30 minutes. This MAE treatment resulting pectin with equivalent weight meet the IPPA standard. High equivalent weight of sample in this treatment is associated with high ash content in this pectin product as has been described earlier in section 3.2b. Overall pectin quality resulted from this study is tabulated in Table 1. 


\section{Conclusion}

This study concludes microwave energy can be utilized to generate energy required to extract pectin from cocoa pod husk using citric acid or $\mathrm{HCl}$ as solvent. MAE performance in this study is influenced by both microwave power and extraction time. Microwave power always associate with extraction temperature.

Pectin quality yielded from extraction either with citric acid or $\mathrm{HCl}$ in this study meet the IPPA quality factor. Exclude water content which relatively higher as compare to treatment with $\mathrm{HCl}$, over all treatment with citric acid for 30 minutes resulted higher pectin quality as compare to treatment with $\mathrm{HCl}$. The best result obtained from treatment using microwave power of 300 Watt for approximately 30 minutes. Pectin obtained from this combination of power and time resulted yield of $42 \%$ with characteristic: moisture content of $8 \%$, ash content of $10 \%$, equivalent weight of $714.29 \mathrm{mg}$, methoxyl content of $4.8 \%$ and galacturonate level of $43 \%$.

\section{Acknowledgements}

This research funded by Universitas Sumatera Utara in accordance with TALENTA Research Implementation Contract of Universitas Sumatera Utara under fiscal year of 2018 .

\section{References}

British Standard. (1998) Methods for Analysis and Testing Coal and Coke. Proximate Analysis, British Standard Institution

Chan, S.Y. and Choo, W.S. (2013) Effect of extraction conditions on the yield and chemical properties of pectin from cocoa husks. Food Chemistry, 141, 3752-3758

Chen, Y., Zhang, J.G., Sun, H.J. \& Wei, Z.J. (2014) Pectin from Abelmoschus esculentus: Optimization of extraction and rheological properties. International Journal of Biological Macromolecules, 70, 498-505

Cheng, S. F., Nor L, M. and Chuah, C. H. (2011). Microwave pretreatment: A clean and dry method for palm oil production. Industrial Crops and Products, 34(1), 967-971.

Coates, J. (2006) Interpretation of Infrared Spektra, A Practical Approach. Encylopedia of Analytical Chemistry, 10.1002/9780470027318.a5606

Cruess, W.V. (1958) Commercially Fruits and Vegetable Products, New York, McGraw Hill Book Constenla, D and Lozano, J.E. (2003) Kinetic Model of Pectin Demethylation. Latin American Applied Research, 33, 91-96

Devi, E.W., Shukla, R.N., Bala, K.L., Kumar, A., Mishra, A.A. \& Yadav, K.C. (2014) Extraction of Pectin from Citrus Fruit Peel and Its Utilization in Preparation of Jelly. International Journal of Engineering Research \& Technology (IJERT), 3(5), 1925-1932

Dhiraj, M., Krishnacharya, P. \& Akamanchi, G. (2017) Microwave assisted process intensification and kinetic modelling: Extraction of camptothecin from Nothapodytes nimmoniana plant. Industrial Crops and Products, 98, 6067

International Pectin Producers Association. (2014) Pectin Commercial Production and Pectin in Organic Food Products
Kalapathy, U. and Proctor, A. (2001) Effect of acid extraction and alcohol precipitation conditions on the yield and purity of soy hull pectin. Journal Food Chemistry, 73, 393-396

Lefsih, K., Giacomazza, D., Dahmoune, F., Mangione, M.R., Bulone, D., San Biagio, P.L., Passantino, R., Costa, M.A., Guarrasi, V. and Madani, K. (2017) Pectin from Opuntia ficus indica: Optimization of microwave-assisted extraction and preliminary characterization. Food Chemistry, 221, 9199

Manrique, G.D. and Lajolo,F.M. (2002) FT-IR spectroscopy as a tool for measuring degree of methyl esterification in pectins isolated from ripening papaya fruit. Postharvest Biology and Technology, 25(1), 99-107

Maran, J.P. (2015) Statistical optimization of aqueous extraction of pectin from waste durian rinds. International Journal of Biological Macromolecules, 73, 92-98.

Oliveira, C.F., Giordani, D., Lutckemier, R., Gurak, P.D., F. Cladera-Olivera, F. \& Marczak,L.D.F. (2016) Extraction of pectin from passion fruit peel assisted by ultrasound. $L W T$ Food Science and Technology, 71, 110-115

Qiu, L.P., Zhao, G.I., Hui, W., Lu, J., Li X.F. \& Liu, J.J. (2010) Investigation of combined effects of independent variables on extraction of pectin from banana peel using response surface methodology. Carbohydrate Polymers, 80, 326-331

Ranggan. S. (2000) Handbook of Analysis and Quality Control for Fruit and Vegetable Product. $2^{\text {nd }}$ Edition. McGraw-Hill Publishing Company Limited, New Delhi, 35

Santos, J.D.G., Espeleta, A.F., Branco, A. \& de Assis, S.A. (2013) Aqueous extraction of pectin from sisal waste. Carbohydrate Polymers, 92(2) 1997-2001

Sarah, M. (2018) Carotenoids Preservation During Sterilization of Palm Fruit Using Microwave Irradiation. ARPN Journal of Engineering and Applied Sciences, 13(3), 1009-1014

Sarah, M. and Taib, M.R. (2017) Critical parameters for sterilization of oil palm fruit by microwave irradiation. AIP Conference Proceedings 1879

Sarah, M., Hanum, F., Rizki, M. \& Hisham, M.F. (2018) Microwave-assisted extraction of pectin from cocoa peelIOP Conference Series: Earth and Environmental Science, 122 (2018)

Sarah, M., Taib, M.R. \& Adamu, A. (2014). Enzymatic Inactivation of Oil Palm Fruits: Comparison of Microwave Irradiation and Steam Bath Process. Jurnal Teknologi, $69: 2,55-60$

Sarah, M., Widyastuti, S. and Ningsih, D. (2018) Red palm oil production by microwave irradiation. IOP Conference Series: Materials Science and Engineering, 309

Shkodina, O.G., Zeltser, O.A., Selivanov N.Y. \& Ignatov, V.V. (1998) Enzymic extraction of pectin preparations from pumpkin. Food Hydrocolloids, 12, 313-316

Sirotek, K.L., Slovakova, J., Kopecny, M. \& Marounek, M. (2014) Fermentation of pectin and glucose, and activity of pectindegrading enzymes in the rabbit caecal bacterium Bacteroides caccae. Letters in Applied Microbiology, 38, 327-332

Sukaribin, N. and Khalid, K. (2009) Effectiveness of sterilisation of oil palm bunch using microwave technology. Industrial Crops and Products, 30(2), 179-183.

Swamy, G.J. and Muthukumarappan, (2017) K. Optimization of continuous and intermittent microwave extraction of pectin from banana peels, Food Chemistry, 220, 108-114.

This article is an extended version of a paper presented at International Conference of Process and Product Engineering (ICCPPE 2019) held on Sept 25, 2019. The article has been reviewed by journal peer-reviewers including complete proofs. 